\title{
Interfaces entre práticas de linguagem e políticas linguísticas: diglossia, crioulidade e ensino de línguas crioulas nas Antilhas francesas
}

Vanessa Massoni da Rocha ${ }^{a}$

\begin{abstract}
Resumo
Neste artigo buscamos analisar os contextos pedagógicos de ensino/aprendizagem das linguas crioulas nos departamentos ultramarinos franceses de Martinica e Guadalupe. Nossas análises se organizam em três eixos que articulam linguas, ensino e culturas literárias. De início, examinamos as diretrizes pedagógicas da Educação nacional francesa para compreender as políticas públicas de ensino das línguas crioulas nas ilhas caribenhas a partir da departamentalização (1946). Em seguida, privilegiamos a importância das línguas crioulas na formação identitária dos povos insulares e na plenitude de suas cidadanias. Por fim, pretendemos observar como a literatura se tornou espaço de tomada de consciência e de questionamento dos rumos identitários, sociais, políticos e culturais na pós-colonização. Neste contexto, muitos escritores caribenhos acolhem em suas produções o ambiente escolar e suas facetas. Trata-se de denunciar escolas dissociadas da realidade crioula e reivindicar um espaço escolar capaz de privilegiar as artes de dizer e viver da crioulidade.
\end{abstract}

Palavras-chave: Politicas públicas. Pós-colonialidade. Práticas linguísticas. Crioulidade. Linguas em contato.

Recebido em 30 de dezembro de 2016 Aceito em 26 de abril de 2017

aProfessora de Língua Francesa e de Literaturas Francófonas da Universidade Federal Fluminense. E-mail: vanessamassonirocha@gmail.com 
Caminhava com minha língua crioula em mim, sua poética, seu ritmo, seus espetáculos. (...) Ela me reinventava o país e as pessoas de maneiras desconhecidas pela língua dominante. (...) Eu fui tomado por árvores, tempos, traços-memórias, nosso mosaico cultural ao ponto de ebulição das linguas crioula-francesa, bem além das palavras.

$\left(\right.$ CHAMOISEAU, 2011, p. 299) ${ }^{1}$

Este artigo se articula em torno de três eixos temáticos. O primeiro eixo temático estuda as diretrizes pedagógicas da Educação Nacional francesa para compreender as políticas públicas de ensino das línguas crioulas nos departamentos ultramarinos antilhanos de Martinica e de Guadalupe. Desejase cotejar estes documentos a testemunhos de educadores que denunciam o grande hiato entre as necessidades educacionais da população caribenha e o ensino praticado no âmbito institucional. Em seguida, privilegiamos a importância das línguas crioulas na formação identitária dos povos insulares e na plenitude de sua cidadania. Observamos especificidades da língua crioula como veículo autêntico do mosaico cultural caribenho. Neste momento, estudamos os fenômenos de descrioulização e recrioulização tal como definidos por Raphaël Confiant, escritor, ensaísta e professor da Université des Antilles et de la Guyane. Por fim, promovemos uma interface entre língua e cultura literária ao contemplarmos obras literárias que denunciam o descompasso entre a escola francesa e a realidade crioula. As obras literárias antilhanas, muitas vezes excluídas das diretrizes de ensino oficiais, se oferecem como instrumentos criativos e legítimos que demonstram a realidade caribenha e a língua crioula silenciadas nos círculos escolares. Trata-se de um movimento cultural no qual as manifestações artísticas criticam as políticas educacionais e se oferecem como possibilidade de promover debates acerca da realidade crioula.

Paulo Freire, patrono da educação brasileira e profundo pensador das articulações entre escola e sociedade, publicou diversas obras de referência para debates acerca das funções e implicações do magistério. Na obra Pedagogia da autonomia,

1 Todas as obras teóricas e literárias cujas referências bibliográficas estão em francês apresentam tradução de nossa autoria. Freire se opõe aos desencontros entre as diretrizes dos programas pedagógicos e a realidade dos alunos perguntando o porquê de não haver maior intimidade entre os ensinamentos escolares e a vida do discente para além dos muros escolares. O questionamento "por que não estabelecer uma necessária 
intimidade entre os saberes curriculares fundamentais aos alunos e a experiência social que eles têm como indivíduos?" (FREIRE, 1998, p. 34) alude à não-sintonia entre a dinâmica do espaço escolar e a dinâmica quotidiana e se torna o grande fio condutor de nossas considerações. Por certo, "uma das tarefas mais importantes da prática educativa-crítica é propiciar as condições em que os educandos em suas relações uns com os outros e todos com o(a) professor(a) ensaiam a experiência profunda de assumir-se. Assumir-se como ser social e histórico, como ser pensante, comunicante, transformador, criador, realizador de sonhos" (FREIRE, 1998, p. 46).

Trata-se de pensar as políticas educacionais como ações inclusivas que criam condições para a autonomia, para as formações identitárias, culturais, sociais, políticas e para o protagonismo do educando nas diversas áreas de sua atuação. Em contraponto à escola libertadora freireana se impõe a escola enquanto aparelho ideológico do estado, como explica Althusser em suas considerações: "A escola recebe as crianças de todas as classes sociais desde o Maternal e, a partir daí, com os novos e igualmente com os antigos métodos, ela lhes inculca, durante anos e anos, no período em que a criança é mais 'vulnerável', imprensada entre o aparelho de Estado Família e o aparelho de Estado Escola, determinados 'savoir-faire' revestidos pela ideologia dominante (língua materna, cálculo, história natural, ciências, literatura), ou muito simplesmente a ideologia dominante em estado puro (moral e cívica, filosofia)" (ALTHUSSER, 2008, p.168). P P r a poder se assumir nas mais diversas perspectivas e esferas, os estudantes precisam se identificar ao projeto pedagógico em vigor, necessitam ser contemplados em sua plenitude nas políticas públicas desenvolvidas pelos órgãos competentes e ensejam ser percebidos como protagonistas-transformadores de suas realidades e de suas comunidades. Estas conquistas se revelam a maior e mais contundente função social do processo ensino/aprendizagem.

Contudo, nas ilhas caribenhas de expressão francesa Martinica e Guadalupe, a realidade pedagógica se mostra mais austera. Do ponto de vista histórico, as referidas ilhas antilhanas foram colônias francesas de 1635 a 1946, tendo recebido mão de obra escrava para o trabalho de produção de mercadorias tropicais como cana de açúcar, rum, cacau, 
café e frutas, principalmente a banana. Em 1946, as ilhas se tornam departamentos ultramarinos franceses, conquistam alguma autonomia, mas permanecem territórios franceses regidos pelas leis da antiga metrópole. Neste contexto, a escola antilhana se inscreve nas premissas da Educação Nacional francesa sendo o Boletim Oficial do Ministério da Educação e Ministério da Investigação (BO) o instrumento de regimento e divulgação das diretrizes nacionais de ensino.

Sylvère Farraudière detalha na obra L'école aux Antilles françaises- Le rendez-vous manqué de la démocratie (2008) o papel central da escola como pilar de sustentação ideológica da empreitada (pós)colonial. Neste sentido, o autor reconhece que a instituição de ensino é a "ferramenta" que estrutura a "a assimilação da colônia à pátria mãe" (FARRAUDIÈRE, 2008, p. 15). Micheline Mannette faz eco às reflexões de Farraudière ao estudar a escola pós-colonial em Guadalupe nos dias de hoje. Ela reconhece na dissertação de mestrado sobre o ensino bilíngue crioulo-francês que "na França, uma política de unificação linguística prevalece na escola republicana e é neste contexto de hierarquização que o ensino bilíngue ou multilíngue acontece. $\mathrm{O}$ resultado desta história resulta em uma visão e práticas normativas da linguagem comum de escolaridade que é susceptível de provocar uma inferiorização ativa da língua regional e o aparecimento de insegurança linguística. Isto ocorre em várias comunidades bilíngues, entre alunos alófonos. Este é também o caso em áreas onde existe uma língua regional ou em lugares que experimentaram a imigração" (MANNETTE, 2015, p. 17).

No que concerne ao acolhimento de particularidades linguísticas no ensino nacional francês, a lei de 11 de janeiro de 1951, conhecida como lei Deixonne, inaugurou a oportunidade de desenvolver um ensino de língua e cultura regionais na escola. Naquele momento, apenas quatro línguas regionais foram mencionadas, a saber: basco, bretão, catalão e occitano. As línguas crioulas só foram reconhecidas no século seguinte, no $\mathrm{BO} \mathrm{n}^{\circ} 33$ de setembro de 2001:

O artigo L. 312-10 do Código de Educação reiterou a possibilidade de proporcionar ensino de línguas e culturas regionais ao longo da escolaridade nas áreas onde elas estão em uso. A educação nacional deve dar vida a este patrimônio cultural, para garantir o desenvolvimento das línguas 
regionais e contribuir para sua transmissão. Esquecer essa responsabilidade não seria um sinal de modernidade. Seria sim um defeito do patrimônio cultural nacional. $\mathrm{O}$ ensino de línguas e culturas regionais promove a continuidade entre o ambiente familiar e social e do sistema educativo, contribuindo para a integração de todos no tecido social de proximidade. Este ensino se aplica atualmente ao basco, bretão, catalão, o córsego, o crioulo, o Gallo etc." (FRANÇA, 2001)

É preciso salientar que quando a lei se refere às mais diversas variedades de crioulo de base francesa em um termo no singular, ela silencia a riqueza das diversas línguas crioulas e suas acentuadas particularidades. Os crioulos martinicano, guadalupense, haitiano, bem como os da Ilha da Reunião e os da Guiana francesa, apenas para citar alguns, são línguas distintas. Neste sentido, mencionar o universo linguístico da crioulidade no singular denota a fragilidade conceitual demonstrada no BO.

Apesar da publicação da lei, alguns hiatos se observam entre sua publicação e a vivacidade do ensino das línguas crioulas nas escolas. Dez anos após sua publicação, Ghislaine Tassius-Marceline apresentou a comunicação "Crioulo, sociedade e ensino: entre rejeição e reivindicação ou reconhecimento" no Colóquio nacional Ensinar o Além mar, ensinar no Além mar em Paris em maio de 2011. Inspetora da Educação Nacional na academia de Guadalupe, TassiusMarceline descortina em sua comunicação as dificuldades da implantação plena da lei de 2001. Ela inicia suas ponderações enumerando as problemáticas existentes:

Como conciliar e harmonizar os objetivos subjacentes à implantação do crioulo nos vários níveis de ensino? Ele deve continuar a ser uma ferramenta simples a serviço do aprendizado de francês, ou ser uma matéria plena? Que lugar acordar a este ensino?" (TASSIUS-MARCELINE, 2011, p. 1)

Estas indagações evidenciam que, apesar da lei tardia, poucos foram os avanços na implementação de um estudo pleno e rico das línguas crioulas. A inspetora denuncia as enormes dificuldades a serem enfrentadas quotidianamente. Ela enumera o número insuficiente de professores, a superlotação das turmas de crioulo no ensino médio, as exaustivas correções do Baccalauréat (provas de acesso às universidades públicas ao término do ensino médio) e, por fim, o fato de atualmente 
apenas um grupo muito reduzido de professores debruçarse nos debates e na redação de um programa de ensino do crioulo. Nesse contexto, nota-se uma clara fragilização do ensino. Por um lado, não há ainda um programa de ensino debatido com a comunidade e elaborado coletivamente. Por outro, não há concursos públicos capazes de assegurar um número satisfatório de professores de crioulo nas escolas. Tassius-Marceline conclui sua apresentação com as seguintes considerações:

Vítima do seu sucesso e popularidade (música, esportes, culinária, intelectuais de renome, etc), mas também e, sobretudo, vítima da situação criada pela presença na França de falantes de origem crioula tendo perdido a prática da língua, o ensino do crioulo é agora reivindicado e se desenvolve com um status diferente. Verdadeira língua estrangeira para muitos desses novos alunos (...), o crioulo levanta novos problemas educacionais para os professores. Tal é o paradoxo da língua estrangeira regional crioula, celebrada por alguns e criticada por outros, que pode vir a ser estudada quase como uma língua estrangeira. (TASSIUSMARCELINE, 2011, p. 9)

Para além das dificuldades no que tange às políticas linguísticas, é preciso reconhecer que, no âmbito do imaginário coletivo, as línguas crioulas costumam ser associadas como idiomas do dominado e do oprimido; em outras palavras, como "línguas de baixo" na estratificação social. Com efeito, as ilhas de Martinica e Guadalupe vivenciam uma inegável diglossia, uma profunda relação de forças que opõe e hierarquiza as línguas crioulas e o francês. Enquanto esta se coaduna ao centro metropolitano, ao saber intelectual e ao poder político, aquelas trazem à tona as humilhações da escravidão, dos trabalhos forçados e da submissão. Nesse sentido, logo após o fim da colonização e do início da departamentalização, muitos eram os falantes de crioulo que vislumbraram no estudo do francês uma maneira de ascender socialmente e poder romper as mazelas quotidianas. Muitos sonhavam em estudar na França e assimilar a cultura francesa como modo de 'embranquecimento social' e como recusa à triste herança colonial. Muitos encarnavam as contradições enumeradas por Frantz Fanon para quem "um antilhano é branco pelo inconsciente coletivo, por grande parte do seu inconsciente pessoal, pela quase totalidade do seu processo de individualização. A cor da 
sua pele (...) é negra. Todos os mal-entendidos provêm deste quiproquó" (FANON, 2008, p. 163).

O escritor e crítico tunisiano Albert Memmi reflete sobre a colonização e seus desdobramentos na obra Retrato do colonizado precedido de retrato do colonizador. Memmi explica os graves conflitos do bilinguismo colonial que dissociam e hierarquizam a língua materna do colonizado e a língua imposta pelo colonizador. Destarte, "no conflito linguístico que habita o colonizado, sua língua materna é a humilhada, a esmagada. E esse desprezo, objetivamente fundado, acaba se tornando seu. Por iniciativa própria, ele começa a afastar essa língua enferma, a ocultá-la aos olhos dos estrangeiros, a só aparecer à vontade na língua do colonizador" (MEMMI, 2007, p. 148). Assim, "ao crioulo foi sempre recusado o estatuto de língua; considerado como 'dialeto', 'jargão', viu-se confinado ao papel de simples meio de comunicação familiar" (DAMATO, 1995, p. 195). Damato aprofunda as discussões ao considerar o crioulo "uma praga no processo de aprendizagem do francês, praga que será preciso erradicar" (DAMATO, 1995, p. 199). Sua influência passa a ser considerada a vilã pelo fracasso escolar no ensino do francês nos departamentos ultramarinos. Nesta atmosfera, não tarda para que a diglossia se torne cada vez acentuada. Glissant lembra-nos premissa imposta nos quadros negros no primeiro dia de aula: "é proibido falar crioulo na sala e no pátio" (GLISSANT, 1977, p.119). A cisão entre as línguas contrapõe as instituições escolares (e administrativas de modo geral) à vida quotidiana cujas músicas, histórias, jogos, gastronomia, fauna e flora reiteram a força identitária das línguas crioulas. Dany Bebel-Gisler reforça o caráter legítimo e militante dos falantes de crioulo ao ponderar que "falar crioulo é fazer barulho, é dizer besteiras, é ser mal-educado, adotar 'um comportamento irracional' (...), demonstrar 'subjetividade', (...) recusar a evidência. Falar crioulo (...) é ofuscar a imagem de marca da instituição escolar" (BEBEL-GISLER, 1981, p. 123-124). Falar crioulo, em outras palavras, consiste em exercer plenamente os encontros que forjam o mosaico identitário das Américas, espaço marcado pela alteridade, pela mestiçagem e pelo encontro dos mais diversos elementos culturais que se crioulizam para compor algo "absolutamente imprevisível, absolutamente novo que é a realidade crioula" (GLISSANT, 1996, p. 15). 
Nas reflexões de Memmi merecem destaque as análises sobre o papel do escritor e sobre as ambiguidades da escola (pós)colonial, que analisaremos mais adiante. Ele afirma que "é muito difícil de sustentar o papel do escritor colonizado: ele encarna todas as ambiguidades, todas as impossibilidades do colonizado, levadas ao último grau... Se ele se obstina em escrever em sua língua, condena-se a falar diante de um auditório de surdos ... uma única saída lhe resta, que é apresentada como natural: que escreva língua do colonizador" (MEMMI, 2007, p.149). Tal "drama linguístico" (MEMMI, 2007, p.148) é corroborado por Glissant, para quem "um mundo reduzido unicamente à sua prática oral seria hoje (...) um povo condenado à morte cultural" (GLISSANT, 1997, p. 543). De fato, o escritor antilhano depara-se, como etapa essencial de sua atividade artística, com a necessidade imperativa de pensar sua língua, de colocar em cena uma surconscience linguística (Lise Gauvin), de forjá-la de maneira crítica a partir de eleições afetivas e políticas que tecem e particularizam seus escritos. Neste contexto, o desafio para os escritores do período póscolonial consiste em superar a complexa condição de "drama linguístico" e sobrepor as fronteiras construídas entre oralidade e escrita, anteriormente intransponíveis. Assim, o "escritor caribenho é, como Sísifo, feliz e trágico de uma só vez; Sua Palavra o identifica a um ser da vertigem" (DEBLAINE, 1992, p.101). Devemos pensar, no entanto, em uma vertigem criativa e estimulante capaz de dar força e frescor à produção literária antilhana.

Elogio da crioulidade, manifesto publicado em 1989 pelo linguista Jean Bernabé e pelos escritores Patrick Chamoiseau e Raphaël Confiant, torna-se um marco nos debates acerca da diglossia linguística nas ilhas. Eis os trechos iniciais da conferência: "Nem europeus, nem africanos nem asiáticos, nós nos proclamamos crioulos. A literatura caribenha ainda não existe. Estamos ainda em um estado de pré-literatura: o de uma produção escrita sem audiência em seu território, ignorando a interação/leitores onde se desenvolve a literatura" (BERNABÉ, CHAMOISEAU, CONFIANT, 2015, p.13-14). Eles enfatizam:

nós nos declaramos crioulos. Declaramos que a Crioulidade é o cimento da nossa cultura e deve reger as fundações da nossa antilhanidade. A Crioulidade é a interação de 
elementos caribenhos, europeus, africanos, asiáticos que o jugo da história reuniu no mesmo solo. (BERNABÉ, CHAMOISEAU, CONFIANT, 2015, p.26-27)

e definem as premissas das produções literárias: enraizamento na oralidade (BERNABÉ, CHAMOISEAU, CONFIANT, 2015, p. 37) e seleção vocabular ("o romancista de expressão crioula deve [...] ser o coletor da palavra ancestral, o jardineiro das novas palavras, o descobridor da crioulidade do crioulo. [...]") (BERNABÉ, CHAMOISEAU, CONFIANT, 2015, p.44).

Ora, tal tomada de consciência do papel do escritor como um artista a exaltar as potencialidades do crioulo ressignifica a dicotomia entre a oralidade do crioulo e a escrituralidade do francês. Se, num primeiro momento, os antilhanos buscavam recusar o crioulo e assumir o francês como veículo para conquistar alguma prosperidade, nesse novo momento o crioulo se torna elemento central da identidade cultural caribenha e precisa ser reivindicado e explorado em todas as suas potencialidades. Ralph Ludwig explica que "o arquipélago é um lugar de contato e diálogo entre o mundo europeu da escrita, da alfabetização e das tradições literárias, por um lado, e o mundo da oralidade, do crioulo, do contador de histórias e das festas populares, por outro lado. É a análise deste aspecto particular da situação cultural - a divisão entre escrituralidade do francês e a oralidade do crioulo - que segue a força motriz da literatura do Caribe" (LUDWIG, 1994, p.15).

Certamente, o empreendimento literário franco-crioulo inaugura, em todas as áreas e junto a diversos tipos de público leitor, uma nova era de protagonismo e de tomada de consciência identitária capaz de abarcar a riqueza, as ambiguidades e as contradições da vida pós-colonial. Trata-se de uma profunda transformação nos costumes e nas maneiras de compreender e de registrar a história de ontem e de hoje na Martinica e em Guadalupe: o apogeu de uma "visão interior" (BERNABÉ, CHAMOISEAU, CONFIANT, 2015, p. 23) capaz de superar os longos momentos de "autodepreciação" (BERNABÉ; CHAMOISEAU; CONFIANT, 2015, p.24) engendrados com os desdobramentos da condição colonial.

Dentro deste debate, se elevam vozes de escritores e intelectuais que bradam, denunciam e militam em seus textos contra uma escola que mantém um perfil colonialista e que não 
toma iniciativas para a presença fundamental da língua crioula em seu programa. Vozes que são entoadas contra o discurso pedagógico, que "não exclui apenas o povo da política, mas exclui a política da história, em um movimento de assepsia em que não há lugar para o econômico, o ideológico, para as relações de poder" (SILVA, 2007, p.153). Uma assepsia que transforma a riqueza bilíngue em "sofrimento diglóssico" (BERNABÉ, CHAMOISEAU, CONFIANT, 2015, p. 25).

Em muitas escolas a língua crioula constitui uma matéria facultativa dissociada da realidade. Tal conjuntura é denunciada por Raphaël Confiant no artigo "mês do crioulo" no qual ele preconiza que "o crioulo é uma língua em extinção; O crioulo sofreu uma descrioulização tanto quantitativa (o número de falantes diminui) e qualitativo (qualidade da linguagem tornouse problemática)". A propósito das políticas públicas, ele observa que "os políticos, independentemente de serem 'nacionalistas' ou 'separatistas' nunca elegeram a questão da língua um dos pontos fortes de suas reivindicações, ao contrário do que acontece em situações comparáveis (Córsega, Taiti, Québec, Bretanha, Kabylie etc)". Confiant acrescenta, ainda que

é urgente definir um uma política linguística e defender o estatuto de língua obrigatória desde o ensino primário; Esta política, que visa a desenvolver o nosso ecossistema linguístico, pode ser implementada apenas pela criação de uma Secretaria da língua crioula (CONFIANT, 2016)

Confiant denuncia igualmente em seus escritos a crescente descrioulização na Martinica e em Guadalupe. Para o escritor, "passamos do 'crioulo língua materna' (gerações nascidas antes de 1950) ao 'crioulo língua co-materna' e depois ao "crioulo língua matricial" (geração do fim do século XX início do século XXI). A escolarização total, a generalização do rádio e da televisão (e a multiplicação dos canais de televisão), a chegada da Internet, a facilidade das viagens ao Hexágono, a presença de uma importante comunidade 'metrô', o número de casais 'mistos'..." (CONFIANT, 2016). Este cenário contribuiu para o fenômeno de "francisação linguística massiva" que modificou os espaços de atuação das línguas crioulas.

Ora, o papel da escola em não assegurar o ensino das línguas crioulas se torna um dos grandes pilares para a descrioulização. $\mathrm{O}$ desafio que se impõe atualmente consiste 
em oferecer o ensino das línguas crioulas em busca de uma recrioulização linguística. Albert Memmi explica o desenlace entre a escola (pós)colonial e os discentes. Acerca dos programas curriculares privilegiados, o pesquisador afirma que "a memória que é constituída para ela seguramente não é a de seu povo. A história que lhe é ensinada não é a sua" (MEMMI, 2007, p. 145) e que "os livros o entretêm com um universo que em nada lembra o seu" (MEMMI, 2007, p. 145). No que tange à relação entre mestres e alunos, ele constata que "a transferência não se faz, nem da criança para o professor, nem (muito frequentemente, é preciso confessar) do professor para a criança; e isso a criança sente perfeitamente. Um dos meus antigos colegas de turma me confessou que a literatura, as artes, a filosofia tinham permanecido efetivamente estrangeiras, como se pertencessem a um mundo estrangeiro, o da escola" (MEMMI, 2007, p. 146). Por fim, ele mostra o descompasso entre a escola fiel aos paradigmas coloniais e a realidade da comunidade ao constatar que "se a transferência acaba não se realizando, não é sem riscos: o professor e a escola representam um universo diferente demais do universo familiar. Nos dois casos, enfim, longe de preparar o adolescente para se encarregar totalmente de si mesmo, a escola estabelece em seu íntimo uma definitiva dualidade" (MEMMI, 2007, p.146).

Demerval Saviani discursa sobre o valor dos professores ao vincular sua prática com a prática social global. Para o pedagogo, "a instrumentalização desenvolver-se-á como decorrência da problematização da prática social, atingindo o momento catártico que concorrerá na especificidade da literatura etc. para alterar qualitativamente a prática dos alunos como agentes sociais" (SAVIANI, 2003, p. 80). Em um contexto escolar de minimização das potencialidades das línguas crioulas, as produções literárias se oferecem como espaço fecundo para retratar a língua e a realidade crioulas e para a reconciliação do presente globalizado às tradições orais em latente perigo de desaparecimento. Levando-se em conta o paradigma de que "a literatura reflete questões essenciais para os povos" (GLISSANT, 1997, p. 544), "Glissant atribui ao romancista a tarefa de suprir as falhas existentes nas histórias das colonizações. (...) A literatura nos povos emergentes teria então sua função política enfatizada. Permitir que a história 
dos povos dominados se estabeleçam, adquiram cidadania" (DAMATO, 1995, p.190).

Para uma breve ilustração, algumas passagens de obras da guadalupense Simone Schwarz-Bart e do martinicano Patrick Chamoiseau evidenciam uma ruptura, uma fissura, uma incongruência entre a vida escolar e a vida fora dos muros da escola. No primeiro exemplo, a polícia desconsidera o testemunho do povo negro quando um cadáver foi encontrado: “Essa perseguição feriu dolorosamente o negro. Mas, os mais amargos foram os meninos das escolas, principalmente os 'doutores', que não entendiam por que tinha sido recusado o testemunho das pessoas de Fundo-Zumbi: eles próprios, nos bancos das escolas, não aceitavam as histórias dos brancos no que diz respeito à terra, ao sol e aos astros, o que também não era nada fácil?" (SCHWARZ-BART, 1988, p.35). O trecho seguinte aparece no romance como uma espécie de ladainha demonstrando as imposições a as distorções tecidas nos livros escolares redigidos pelos brancos colonizadores: "Abraçandose, evocavam Wademba e o lado secreto das coisas, essa parte do mundo que não figurava nos livros da escola, pois os brancos haviam decidido colocar um véu por cima..." (SCHWARZ-BART, 1988, p.35).

Em outro trecho, se reitera a premissa da escola enquanto instituição que busca rasurar os personagens locais em busca da reafirmação da história francesa: "você aprendeu as primeiras letras na escola, mas você não encontrará este nome em nenhum livro, pois era o nome de um valoroso, um negro de bem mesmo. E como Obé chegaria até você?" (SCHWARZBART, 1988, p. 61). À liberdade caribenha se contrapõe a censura da crioulidade amplamente promovida em seio escolar, como assinala esta outra passagem da obra: "Na varanda de mãe Vitalina alguns jovens conversavam sobre os novos tempos. Evocavam a recente greve e até a morte e diziam que era preciso refazer tudo no negro; coração, cabeça, entranhas, e talvez seria preciso também regulamentar a palavra, pois, olhem só, suspiravam com amargura: o negro fala e vê a lua ao meio-dia" (SCHWARZ-BART, 1988, p. 83).

Em seguida, acompanhamos a descrição da desastrosa vida escolar relatados por Patrick Chamoiseau no texto autobiográfico Une enfance créole II, segundo livro de uma trilogia dedicada às rememorações infantis. $\mathrm{O}$ segundo tomo 
Chemin d'école coloca em cena os controversos sentimento e aprendizados ao longo da vida escolar. Composto de duas partes nomeadas de envie [desejo, vontade] e survie [sobrevivência], o romance acompanha os grandes desencontros entre a curiosidade da criança que se imagina no universo atrás dos muros da escola e a constatação incrédula de todo o tipo de violência e de divergências entre o ensino formal promovido pelo estado e as práticas culturais vivenciadas no quotidiano. "O negrinho cometeu o erro de pedir a escola" (CHAMOISEAU, 2014, p. 17). É a partir desta confissão que se inicia a narrativa de Chamoiseau e que os tons de incredulidade e de denúncia se impõem como forças motoras da tessitura literária. Outros trechos como "Man Salinière lhe deu papel e lápis de cor. Ela lhe mostrou estranhas imagens de neve e o fez cantar coisas doces de Bretanha ou de Provence." (CHAMOISEAU, 2014, p.39) e "o sinal não provocava nada além de um irrepreensível frisson de prazer que deviam dissimular dos olhares do professor que vigiava" (CHAMOISEAU, 2014, p. 60) compõem o numeroso mosaico das tristes aventuras escolares. Por um lado, as tarefas solicitadas se mostravam profundamente dissociadas da realidade caribenha e, por outro, o sinal para o início do recreio descortinava a alegria dos momentos da recreação e de suspensão das amarguras experimentadas nos bancos da sala de aula. As aulas como meras reproduções de conteúdos programáticos que rechaçavam a realidade para além dos muros e o recreio como espaço e promessa de liberdade, transgressão, brincadeiras e autenticidade.

Por fim, há reiteradas denúncias do funcionamento autoritário de uma escola não somente incapaz de acolher a realidade crioula em seu espaço, mas, sobretudo, empenhada em vociferar os preceitos identitários da metrópole francesa. Fanon afirma que "nas Antilhas, o jovem negro, que, na escola, não para de repetir 'nossos pais, os gauleses', identifica-se com o explorador, com o civilizador, com o branco que traz a verdade aos selvagens, uma verdade toda branca". (FANON, 2008, p. 132). Chamoiseau compartilha em suas narrativas memorialísticas um episódio segundo o qual um aluno é encaminhado à diretoria escolar por conhecer seu nome apenas em crioulo (CHAMOISEAU, 2014, p. 55), fato que o impediu de responder à chamada. 
Certamente, essas iniciativas literárias reiteram momento de tomada de discurso e de protagonismo capazes de ressaltar a riqueza, as ambiguidades e contradições da vida (pós)colonial. Como salienta Pêcheux, "os indivíduos são interpelados em sujeitos-falantes (em sujeitos de seu discurso) pelas formações discursivas que representam "na linguagem" as formações ideológicas que lhes são correspondentes." (PÊCHEUX, 1995, p. 161). A partir desta perspectiva, a exaltação da crioulidade em todas as suas facetas denota uma profunda transformação dos costumes e hábitos e da forma de entender e registrar a história de ontem e de hoje nas ilhas. Trata-se de estabelecer, via fazeres e culturas literárias, uma necessária intimidade entre os saberes curriculares fundamentais aos alunos e à experiência social que eles têm como indivíduos. Trata-se de reforçar o mosaico cultural vislumbrado no "ponto de ebulição das línguas crioulo-francesa, bem além das palavras" (CHAMOISEAU, 2011, p. 299).

\section{REFERÊNCIAS}

ALTHUSSER, L. Sobre a reprodução. Rio de Janeiro: Vozes, 2008. BEBEL-GISLER, D. La langue créole, force jugulée. Paris: l'Harmattan, 1981.

BERNABE, J., CHAMOISEAU, P., CONFIANT R. Éloge de la créolité. Paris: Gallimard, 2015.

CHAMOISEAU, P. Écrire en pays dominé. Paris: Gallimard, 2011. CHAMOISEAU, P. Une enfance créole II - chemin d'école. Paris: Gallimard, 2014.

CONFIANT, R. Le mois du créole. 2016. Disponível em : <https:// www.montraykreyol.org/article/mois-du-creole-lindispensablerecreolisation-linguistique>. Acesso em 26 dez. 2016.

DAMATO, D. Édouard Glissant: Poética e política. São Paulo: Annablume, 1995 (coleção Parcours).

DEBLAINE, D. La loquèle antillaise. Littérature, n.85, p.81-102, 1992. Disponível em: < http://dx.doi.org/10.3406/litt.1992.2605 >. Acesso em 29 dez. 2016.

FANON, F. Pele negra, máscaras brancas. Salvador: EDUFBA, 2008. FARRAUDIÈRE, S. L'école aux Antilles françaises. Le rendez-vous manqué de la démocratie. Paris: L’Harmattan, 2007. 
FRANÇA. Ministère de l'Education Nationale. Bulletin Officiel du ministère de l'Education Nationale et du ministère de la Recherche, N.33 du 13 september 2001. Disponível em <http:// www.education.gouv.fr/bo/2001/33/default.htm>. Acessado em: 29 dez. 2016.

FREIRE, P. Pedagogia da autonomia - saberes necessários à prática educativa. São Paulo: Editora Paz e terra, 1998.

GAUVIN, L. Langagement - L'écrivain et la langue au Québec. Québec: Éd. du Boréal, 2000.

GLISSANT, E. Le discours antillais. Paris: Gallimard, 1977.

GLISSANT, E. Introduction à une poétique du divers. Paris: Gallimard, 1996.

LUDWIG, R. Écrire la «parole de nuit». In : (ed.) Écrire la «parole de nuit»: la nouvelle littérature antillaise. Paris: Gallimard, 1994.

MANNETTE, M. Enjeux d'un enseignement bilingue créole-français en maternelle en Guadeloupe. 2015. 89 f. Dissertação (Mestrado em Ensino, Educação e Formação). Université des Antilles. Guadalupe. 2015. Disponível em : <https://dumas.ccsd.cnrs. fr/dumas-01193735/document>. Acesso em 29 dez. 2016.

MEMMI, A. Retrato do colonizado precedido do retrato do colonizador. Rio de Janeiro: Civilização brasileira, 2007.

PÊCHEUX. M. Semântica e discurso: uma crítica a afirmação do óbvio. Campinas, SP: UNICAMP, 1995.

SAVIANI, D. Escola e democracia. Campinas: Autores associados, 2003.

SCHWARZ-BART, S. Joãozinho no Além. Rio de Janeiro: Livraria Francisco Alves Editora, 1988.

SILVA, M. V. A escolarização da língua nacional. In: ORLANDI, E. (org.). Política Linguística no Brasil. Campinas: Pontes, 2007. TASSIUS-MARCELINE, G. Créole, société et enseignement : entre rejet et revendication ou reconnaissance. Colloque national « Enseigner l'Outre-mer, enseigner en Outre-mer » Paris, 1718 mai 2011. Disponível em <http://media.eduscol.education. fr/file/ Formation_continue_enseignants/24/2/Outre-merTassius-2011_188242.pdf>. Acesso em: 29 dez. 2016. 


\section{Abstract \\ Interfaces between language practices and linguistic policies: diglossia, creoleness and teaching of creole languages in the French Antilles}

In this article we seek to analyse the pedagogical teaching/learning contexts of creole language in the French overseas departments of Martinique and Guadeloupe. Our analyses are organized in three axes that articulate language, teaching and literary cultures. At first, we examine the pedagogical French national guidelines to understand public politics of creole languages in the Caribbean Islands from the departmentalization (1946). Then, we focus on the importance of creole languages in the identity formation of island peoples and in the fullness of their citizenship. Finally, we intend to observe how the literature became space of awareness and of questioning of identity, social trends, political and cultural post-colonization. In this context, many Caribbean writers welcome in their production the school environment and their facets. It is decoupled from reality Creole schools report and claim a school space capable of promoting the arts to say and live on creoleness.

Keywords: Public policies. Post-coloniality. Linguistic practices. Creoleness. Languages in contact. 